Case Report

\title{
Very Early Onset of Therapy-Related Acute Myeloid Leukemia with 11q23 Rearrangement Presenting with Unusual PET Findings after R-DA-EPOCH for Primary Mediastinal Large B-Cell Lymphoma
}

Chrysovalantou Chatzidimitriou ${ }^{1,+}{ }^{+}$, Phivi Rondogianni ${ }^{2,+}{ }^{+}$, Maria Arapaki ${ }^{1}$, Athanasios Liaskas ${ }^{1}$, Eleni Plata ${ }^{1}$, Maria K. Angelopoulou ${ }^{1}$, Panagiotis Tsirigotis ${ }^{3, \ddagger}$ and Theodoros P. Vassilakopoulos ${ }^{1, *, \ddagger(D)}$

1 Department of Haematology and Bone Marrow Transplantation, School of Medicine, National and Kapodistrian University of Athens, Laikon General Hospital, 11527 Athens, Greece; cchatzidimitriou@hotmail.com (C.C.); arapaki_m@hotmail.gr (M.A.); ath.liaskas@gmail.com (A.L.); eleniplata@gmail.com (E.P.); mkangelop@gmail.com (M.K.A.)

2 Department of Nuclear Medicine and PET/CT, Evangelismos General Hospital, 10676 Athens, Greece; phrontog@yahoo.gr

3 Second Department of Internal Medicine, Propaedeutic, School of Medicine, National and Kapodistrian University of Athens, Attikon General Hospital, 12462 Athens, Greece; panagtsirigotis@gmail.com

check for

updates

Citation: Chatzidimitriou, C.

Rondogianni, P.; Arapaki, M.; Liaskas, A.; Plata, E.; Angelopoulou, M.K.; Tsirigotis, P.; Vassilakopoulos, T.P. Very Early Onset of TherapyRelated Acute Myeloid Leukemia with 11q23 Rearrangement Presenting with Unusual PET Findings after R-DA-EPOCH for Primary Mediastinal Large B-Cell Lymphoma. Medicina 2022, 58, 48. https://doi.org/10.3390/medicina 58010048

Academic Editor: Mauro Salvatore Alessandro Alaibac

Received: 9 November 2021

Accepted: 24 December 2021

Published: 29 December 2021

Publisher's Note: MDPI stays neutral with regard to jurisdictional claims in published maps and institutional affiliations.

Copyright: (C) 2021 by the authors. Licensee MDPI, Basel, Switzerland. This article is an open access article distributed under the terms and conditions of the Creative Commons Attribution (CC BY) license (https:// creativecommons.org/licenses/by/ $4.0 /)$
* Correspondence: tvassilak@med.uoa.gr or theopvass@hotmail.com; Tel.: +30-213-2061702; Fax: +30-213-2061498

+ These authors contributed equally to this work.

$\ddagger$ These authors contributed equally to this work.

\begin{abstract}
Background: R-DA-EPOCH is an effective regimen for PMLBCL, which permits the omission of consolidative radiotherapy in the majority of patients. Patient: We describe a 27-year-old female patient, who achieved a complete remission after treatment with six cycles of R-DA-EPOCH (up to the final level). At 6 months after the end of treatment, PET/CT revealed an unexpected, diffusely increased ${ }^{18}$ FDG uptake by the bone marrow. Simultaneously, pancytopenia with monocytosis was observed. Result: The patient was diagnosed with therapy-related myelodysplastic syndrome, which rapidly evolved into acute myeloid leukemia (t-MDS/AML) with MLL rearrangements. She achieved a complete remission after induction therapy, received an allogenic transplant and remains disease-free 2 years later. Conclusions: The extremely early onset of $\mathrm{t}$-MDS/AML, together with the unexpected PET/CT findings make this case unique and highlights the need for the accurate estimation of the possible dose-dependent risk of t-MDS/AML after R-DA-EPOCH in the real-life setting in patients with PMLBCL.
\end{abstract}

Keywords: primary mediastinal large B-cell lymphoma; R-DA-EPOCH; etoposide; therapy-related; acute myeloid leukemia

\section{Introduction}

Primary mediastinal large B-cell lymphoma (PMLBCL) is a rare disease of young adults, with a female predominance [1]. The combination of rituximab, cyclophosphamide, doxorubicin, vincristine and steroids (R-CHOP) has greatly improved the results of CHOP alone $[2,3]$ and has become a reasonable standard of care, usually followed by consolidation radiotherapy. The young age of the patients and the female predominance makes the use of radiotherapy worrisome because of concerns of delayed effects. Although positron emission tomography/computed tomography (PET/CT) may facilitate the omission of radiotherapy after R-CHOP [4-6], this remains to be formally addressed by the International Extranodal Lymphoma Study Group (IELSG) randomized trial IELSG-37 [7].

The combination of rituximab with dose-adjusted etoposide, steroids, vincristine, cyclophosphamide and doxorubicin (R-DA-EPOCH) produced impressive results in phase 
2 studies $[8,9]$. Although disease control may be somewhat inferior in real-life case series, R-DA-EPOCH certainly permits the omission of radiotherapy in the overwhelming majority of the patients, thus avoiding potential malignant or non-malignant late toxicity [8-13].

R-DA-EPOCH contains topoisomerase II inhibitors, namely etoposide and doxorubicin, and the alkylating agent, cyclophosphamide. Starting from a baseline level (level 1), the doses of these drugs can be escalated according to the patient's tolerance and disease response up to the sixth or even eighth level [8]. However, these drugs are potentially leukemogenic, as clearly shown in Hodgkin lymphoma after BEACOPP-escalated (bleomycin, etoposide, doxorubicin, cyclophosphamide, vincristine, procarbazine and prednisone) $[14,15]$. Cases of therapy-related myelodysplastic syndrome and acute myeloid leukemia (t-MDS/AML) are extremely rarely reported after R-DA-EPOCH $[8,16]$.

We describe here an exceptional case of t-MDS/AML after R-DA-EPOCH for PMLBCL with extremely early onset after the end of immunochemotherapy, presented with unexpected findings on follow-up PET/CT, which highlighted the challengedof potential leukemogenicity in this young population.

\section{Case Report}

A 27-year-old female was diagnosed with PMLBCL during the evaluation of a $17 \mathrm{~cm}$ mediastinal mass extending to the right lung and the pericardium, a large pericardial effusion and a $5.5 \times 4.0 \mathrm{~cm}$ spleen lesion. A bone marrow aspiration and biopsy did not reveal lymphomatous infiltration or dysplastic changes. She received six R-DA-EPOCH cycles reaching the highest dose level +6 [8]. More specifically, R-DA-EPOCH level 1 refers to the starting dose level as follows: etoposide $50 \mathrm{mg} / \mathrm{m}^{2}$ on days $1-4$ (total $200 \mathrm{mg} / \mathrm{m}^{2}$ ), prednisone $60 \mathrm{mg} / \mathrm{m}^{2}$ ondays $1-5$, vincristine $0.4 \mathrm{mg} / \mathrm{m}^{2}$ on days $1-4$, cyclophosphamide $750 \mathrm{mg} / \mathrm{m}^{2}$ on day 5 , and doxorubicin $10 \mathrm{mg} / \mathrm{m}^{2}$ on days $1-4$ (total $40 \mathrm{mg} / \mathrm{m}^{2}$ ). At each of the following cycles, doses are adjusted by a $20 \%$ increase above the last cycle or by a $20 \%$ reduction (up to level-2) based on the neutrophil and platelet nadir observed in the previous cycle. Dose adjustments above level +1 apply to etoposide, doxorubicin and cyclophosphamide, and adjustments below level +1 only apply to cyclophosphamide [8]. In the case of uneventful escalation to level +6 , as was the case with this patient, the final doses were roughly $124 \mathrm{mg} / \mathrm{m}^{2}$ on days $1-4$ (total $1986 \mathrm{mg} / \mathrm{m}^{2}$ ) for etoposide in $96 \mathrm{~h}$ continuous infusion, $99 \mathrm{mg} / \mathrm{m}^{2}$ on days $1-4$ (total $397 \mathrm{mg} / \mathrm{m}^{2}$ ) for doxorubicin in $96 \mathrm{~h}$ continuous infusion, and $1866 \mathrm{mg} / \mathrm{m}^{2}$ on day 5 (total $7447 \mathrm{mg} / \mathrm{m}^{2}$ ) for cyclophosphamide. The clinical course was complicated by pericarditis, treated with non-steroidal, anti-inflammatory drugs (NSAID) and a short course of corticosteroids.

${ }^{18}$ FDG-PET/CT performed 1 and 3 months post-R-DA-EPOCH, without further intervention in the meantime, demonstrated rather mild ${ }^{18} \mathrm{FDG}$ uptake interpreted as a Deauville 5-point scale score (D5PSS) of 4 and 3, respectively, with the uptake localized to the $6.6 \mathrm{~cm}$ residual mediastinal mass and the pericardium. Although this might indicate active disease, especially after R-CHOP or R-MACOP-B (combination of rituximab, methotrexate, doxorubicin, cyclophosphamide, vincristine, prednisone, bleomycin) [4-6], a positive PET/CT (especially D5PSS4) after R-DA-EPOCH does not mandate the use of radiotherapy $[8,9]$.

${ }^{18}$ FDG-PET/CT obtained 6 months after R-DA-EPOCH completion (10.6 months after treatment initiation) revealed an increased, peripheral, "ring-like" ${ }^{18} \mathrm{FDG}$ uptake by the residual large mediastinal mass (SUVmax ${ }_{\text {lesion }}$ : 4.0 versus SUVmax ${ }_{\text {liver }}$ : 2.6-Figure 1: b, white arrow; d, black arrow), again interpreted as D5PSS4, but with no increase in mediastinal mass size. Unexpectedly, there was a diffusely increased ${ }^{18} \mathrm{FDG}$ bone marrow (BM) uptake with an intensity exceeding that of the liver (Figure 1a,c,d) in the absence of recent granulocyte colony stimulating factor (G-CSF) use. Although this pattern of BM uptake was not consistent with BM infiltration by PMLBCL, which would be expected to be multifocal $[17,18]$, further clinical evaluation was recommended. 

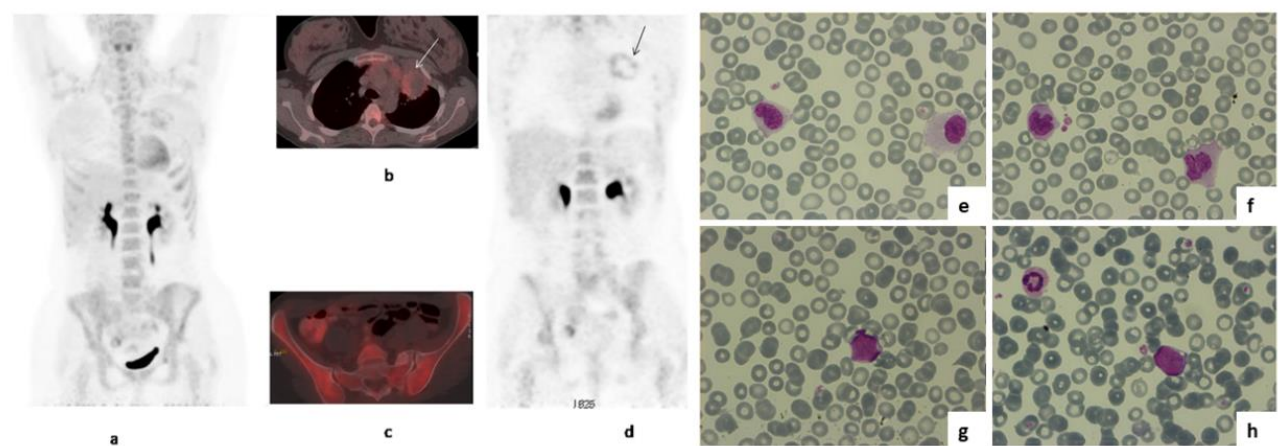

Figure 1. MIP (a) axial-fused (b,c) and coronal PET images (d) of ${ }^{18}$ FDG PET /CT performed during the patient's follow up, 6 months after the completion of treatment with R-DA-EPOCH. There is diffusely increased ${ }^{18}$ FDG uptake by the bone marrow with intensity higher than that of the liver $(\mathbf{a}, \mathbf{c}, \mathbf{d})$. As no Granulocyte Colony Stimulating Factor (G-CSF) was administered, this was a new finding. Increased peripheral, "ring like" ${ }^{18}$ FDG uptake by the residual large mediastinal mass was also present with intensity higher than that of the liver-SUVmax $\operatorname{lesion}_{\text {- }}: 4$ versus SUVmax $\operatorname{liver}_{2,6}$ (b white arrow, $\mathbf{d}$ black arrow). Peripheral blood smear simultaneously revealed abnormal monocytes $(\mathbf{e}, \mathbf{f})$, and blast cells appeared one month later, when the evolution of t-MDS into acute myeloid leukemia was demonstrated $(\mathbf{g}, \mathbf{h})$.

Blood counts were as follows: Hematocrit $35.3 \%$, hemoglobin $12.3 \mathrm{~g} / \mathrm{dL}$, WBC $3.85 \times 10^{9} / \mathrm{L}$ (neutrophils $0.89 \times 10^{9} / \mathrm{L}$, lymphocytes $0.67 \times 10^{9} / \mathrm{L}$, monocytes $1.88 \times 10^{9} / \mathrm{L}$ ), platelets $98 \times 10^{9} / \mathrm{L}$. Abnormal monocytes (Figure 1e,f) were observed in the peripheral blood smear. Bone marrow aspiration and immunophenotype at that time revealed a population of CD34+ CD117+CD13+CD33-HLA-DR+ cells, which consisted of only $1 \%$ of CD45+ cells, whereas the percentage of CD64+ cells of the monocytic lineage was 25\%, including 12\% CD64+CD14- cells. Molecular analysis with reverse transcriptase polymerase chain reaction (RT-PCR, sensitivity of the assay: $10^{-4}$ ) and karyotype revealed the presence of Mixed-Lineage Leukemia gene (MLL) rearrangement $(\mathrm{t}(9 ; 11)(\mathrm{p} 21 ; \mathrm{q} 23) ;(\mathrm{AF9}-\mathrm{MLL}))$. One month later, the patient progressed to overt t-AML (Figure $1 \mathrm{~g}, \mathrm{~h}$ ), as a repeat bone marrow biopsy revealed $85 \%$ infiltration by blasts expressing HLA-DR, MPO, CD15, PGM-1, CD56, c-kit and CD99 (Figure 1g,h). The 11q23 rearrangement was not detectable, in retrospect, in the pre-R-DA-EPOCH BM sample. The patient achieved a complete remission with the combination of mitoxanthrone, fludarabine, high-dose cytarabine and G-CSF (Nova-FLAG) induction therapy and received one cycle of FLAG consolidation. Subsequently, she was forwarded to a sibling-matched allotransplant and remains in complete remission 32 months later without clinically significant complications.

\section{Discussion}

R-DA-EPOCH is a very effective regimen and obviates the need for radiotherapy in PMLBCL [8-13]. High-doses of etoposide, doxorubicin and cyclophosphamide may be complicated by t-MDS/AML. Etoposide and doxorubicin typically cause earlier t-MDS / AML events within 1-5 years from treatment, usually bearing MLL rearrangements, while cyclophosphamide and other alkylating agents cause more delayed t-MDS/AML, carrying complex karyotypes and/or chromosome 5 and 7 abnormalities [1].

The risk of developing t-MDS/AML after R-DA-EPOCH was not thoroughly evaluated. Although R-DA-EPOCH is a popular regimen, especially in the United States, the number of patients that were analyzed in the literature is rather limited and fall within diverse clinical scenarios. In the original R-DA-EPOCH study in PMLBCL, 1/51 patients developed rather late t-AML—at 49 months after the completion of treatment-having reached level +3 [8], while in our Hellenic-Italian-Turkish series, 4/190 cases were recorded (including the case reported here) [19]. These figures were comparable resulting in a rough incidence of approximately $2 \%$. No mention of t-MDS/AML was been made in other real-life series of PMLBCL [10-12,20] or other lymphomas [21,22]. In the Intergroup Alliance/Cancer and Leukemia Group B (Alliance/CALGB) randomized trial, 2/241 versus 
1/250 patients treated with R-DA-EPOCH and R-CHOP died of t-MDS/AML [16]. However, the median age of these patients was 58 years ( $>60$ years in $43 \%$ ) and only $30 \%$ reached levels 4-6 (14\% levels 5-6). In contrast, the median age of patients with PMLBCL in the original R-DA-EPOCH study was 30 years with no patient $>60$ years old and $>50 \%$ reached levels 4-6, clearlydue to the much better bone marrow reserves in this young population [8].

This case interestingly illustrates the unexpected PET/CT findings during followup of PMLBCL, namely the diffusely increased ${ }^{18}$ FDG bone marrow uptake, due to the development of t-MDS/AML. However, the present case is exceptional due to the extremely short latency period of 6 months from the end or 10.6 months from the start of chemotherapy, respectively. This is the shortest lag-time between the onset of chemotherapy and AML reported so far, along with a single case among those recently reported by Menghrajani et al. [23]. In addition, only 1 of $\sim 80$ t-MDS/AML cases developed at 10 months from treatment initiation of Hodgkin lymphoma with BEACOPP, another high-doseetoposide and anthracycline-containing regimen, as inferred from Figure 1 of the published article [24]. The cumulative doses of potentially leukemogenic drugs in fully escalated R-DA-EPOCH for six cycles are $1986 \mathrm{mg} / \mathrm{m}^{2}$ for etoposide, $397 \mathrm{mg} / \mathrm{m}^{2}$ for doxorubicin, and $7447 \mathrm{mg} / \mathrm{m}^{2}$ for cyclophosphamide, in comparison to $3600 \mathrm{mg} / \mathrm{m}^{2}, 210 \mathrm{mg} / \mathrm{m}^{2}$, and $7500 \mathrm{mg} / \mathrm{m}^{2}$ for BEACOPP-escalated $\times 6 ; 4800 \mathrm{mg} / \mathrm{m}^{2}, 280 \mathrm{mg} / \mathrm{m}^{2}$, and 10,000 mg $/ \mathrm{m}^{2}$ for BEACOPPescalated $\times 8$; and $2400 \mathrm{mg} / \mathrm{m}^{2}, 200 \mathrm{mg} / \mathrm{m}^{2}$, and $5200 \mathrm{mg} / \mathrm{m}^{2}$ for BEACOPP-baseline $\times 8$. In addition, the BEACOPP variants contain a high cumulative dose of the alkylation agent, procarbazine. All these BEACOPP variants have a well-established leukemogenic potential within large prospective trials, with the risk of t-MDS/AML being $<1 \%$ [15], $3.2-4.0 \%[14,15]$ and $2.2 \%[14,15]$ for BEACOPP-escalated $\times 6$, BEACOPP-escalated $\times 8$, and BEACOPP-baseline $\times 8$, respectively. The causative relationship between the dose of cytotoxic agents and leukemogenic effect is a major issue, as the efficacy of R-DA-EPOCH is based preciselyon the increase in drug dose according to patienttolerance. Usually, younger patients develop less toxicity and reach higher dose levels, thus are theoretically exposed at greater risk of t-MDS/AML. As the development of t-MDS/AML 6 months after the end of R-DA-EPOCH is extremely unusual, the possibility of a pre-existing lesion in this specific case was suspected and actually excluded by RT-PCR in the pretreatment BM sample.

In a previous study of the German AML Study Group, 54/1897 (2.8\%) cases of AML had MLL-rearrangements, more frequently in the group of t-AML (9.4\%) compared with de novoAML (2.6\%). No case with MLL-rearrangement occurred among AML with a previous myelodysplastic or myeloproliferative neoplasm [24]. The MLL gene is fused with $\sim 50$ different partner chromosomal regions, with 9 p22 being the most common and more frequently observed in t-AML compared with de novo cases [25]. The recent WHO classification characterizes $\mathrm{t}(9 ; 11)$ (AF9/MLL) AML as a distinct entity, differentiating it from the heterogenous group of MLL fusions with various other partner genes.

The short time interval between treatment initiation and $\mathrm{t}$-AML raises the possibility that transformation to AML is the direct result of MLL-rearrangement occurring as a first and single event in a primitive hematopoietic progenitor cell. In accordance with this hypothesis, a previous study showed that concurrent driver gene mutations were extremely rare or absent in 286 patients with $\mathrm{t}(11 \mathrm{q} 23) \mathrm{AML}$, with the exception of fms-like tyrosine kinase 3 (FLT3)-activating mutations occurring in $5-10 \%$ of cases [26]. The overexpression of ecotropic virus integration site 1 gene (EVI1) was observed in $45.8 \%$ of all patients with $t(11 q 23)$ and was the only factor significantly associated with a poor outcome [26]. In the group of patients with $\mathrm{t}(9 ; 11)$, EVI1 deregulation was more frequently observed in $\mathrm{t}-\mathrm{AML}$ cases and was associated with higher leukocyte counts at presentation, possibly because EVI1 overexpression confers a high proliferative potential to leukemic blasts [26].

A careful observation of the time intervals between treatment initiation and AML onset reveals that patients reported by Menghrajani et al. are divided in two clusters [23], including 12 and 9 patients who developed AML after a median of 18 months (range, 10.5-22) and 42 months (range, 38-54), respectively. A better characterization of the two groups may facilitate a greater understanding of the biology of MLL-rearranged AML. 
EVI1 deregulation may partly explain the very early occurrence in a subset of leukemias as discussed above.

The risk of $\mathrm{t}-\mathrm{MDS} / \mathrm{AML}$ after R-DA-EPOCH should be accurately quantified and correlated to the reached dose level, especially in the young population of patients with PMLBCL. The accurate prediction of prognosis is required in order to tailor treatment to the individualized risk of failure [27-29] and potentially restrict more toxic chemotherapy to higher-risk patients. Meanwhile, PET/CT might facilitate the omission of radiotherapy in lower-risk patients [4-6,29] in strictly negative patients. Finally, the incorporation of PD-1 inhibitors, which are active in relapsed/refractory disease into the first-line therapy might permit anincrease in efficacy without the toxic effects of more intensive chemotherapy $[30,31]$.

Author Contributions: Conceptualization, T.P.V., P.R., C.C. and P.T.; writing—original draft preparation: T.P.V., P.R., C.C., P.T., M.A. and A.L.; writing-review and editing: T.P.V., P.R., C.C., P.T., M.A., A.L., M.K.A. and E.P. All authors have read and agreed to the published version of the manuscript.

Funding: This research received no external funding.

Institutional Review Board Statement: Not applicable.

Informed Consent Statement: Informed consent was obtained from all involved subjects.

Conflicts of Interest: The authors declare no conflict of interest.

\section{References}

1. Gaulard, P.; Harris, N.L.; Pileri, S.A.; Stein, H.; Kovrigina, A.M.; Jaffe, E.S.; Moller, P.; Gascoyne, R.D. Primary mediastinal (thymic) large B-cell lymphoma. In WHO Classification of Tumours of Haematopoietic and Lymphoid Tissues, 4th ed.; Swerdlow, S.H., Campo, E., Harris, N.L., Jaffe, S.E., Pileri, S.A., Stein, H., Thiele, J., Eds.; International Agency for Research on Cancer (IARC) Publications: Lyon, France, 2017; p. 314.

2. Rieger, M.; Osterborg, A.; Pettengell, R.; White, D.; Gill, D.; Walewski, J.; Kuhnt, E.; Loeffler, M.; Pfreundschuh, M.; Ho, A.D.; et al. Primary mediastinal B-cell lymphoma treated with CHOP-like chemotherapy with or without rituximab: Results of the Mabthera International Trial Group study. Ann. Oncol. Off. J. Eur. Soc. Med. Oncol. 2011, 22, 664-670. [CrossRef]

3. Vassilakopoulos, T.P.; Pangalis, G.A.; Katsigiannis, A.; Papageorgiou, S.G.; Constantinou, N.; Terpos, E.; Zorbala, A.; Vrakidou, E.; Repoussis, P.; Poziopoulos, C.; et al. Rituximab, cyclophosphamide, doxorubicin, vincristine, and prednisone with or without radiotherapy in primary mediastinal large B-cell lymphoma: The emerging standard of care. Oncologist 2012, 17, 239-249. [CrossRef]

4. Vassilakopoulos, T.P.; Pangalis, G.A.; Chatziioannou, S.; Papageorgiou, S.; Angelopoulou, M.K.; Galani, Z.; Kourti, G.; Prassopoulos, V.; Leonidopoulou, T.; Terpos, E.; et al. PET/CT in primary mediastinal large B-cell lymphoma responding to rituximab-CHOP: An analysis of 106 patients regarding prognostic significance and implications for subsequent radiotherapy. Leukemia 2016, 30, 238-242. [CrossRef] [PubMed]

5. Martelli, M.; Ceriani, L.; Zucca, E.; Zinzani, P.L.; Ferreri, A.J.; Vitolo, U.; Stelitano, C.; Brusamolino, E.; Cabras, M.G.; Rigacci, L.; et al. [18F]fluorodeoxyglucose positron emission tomography predicts survival after chemoimmunotherapy for primary mediastinal large B-cell lymphoma: Results of the International Extranodal Lymphoma Study Group IELSG-26 Study. J. Clin. Oncol. Off. J. Am. Soc. Clin. Oncol. 2014, 32, 1769-1775. [CrossRef]

6. Vassilakopoulos, T.P.; Papageorgiou, S.G.; Angelopoulou, M.K.; Chatziioannou, S.; Prassopoulos, V.; Karakatsanis, S.; Arapaki, M.; Mellios, Z.; Sachanas, S.; Kalpadakis, C.; et al. Positron emission tomography after response to rituximab-CHOP in primary mediastinal large B-cell lymphoma: Impact on outcomes and radiotherapy strategies. Ann. Hematol. 2021, 100, $2279-2292$. [CrossRef]

7. Martelli, M.; Zucca, E.; Botto, B.; Kryachok, I.; Ceriani, L.; Balzarotti, M.; Tucci, A.; Cabras, M.G.; Zilioli, V.R.; Rusconi, C.; et al. Impact of Different Induction Regimens on the Outcome of Primary Mediastinal B Cell Lymphoma in the Prospective IELSG 37 Trial. Hematol. Oncol. 2021, 39, 90-91. [CrossRef]

8. $\quad$ Dunleavy, K.; Pittaluga, S.; Maeda, L.S.; Advani, R.; Chen, C.C.; Hessler, J.; Steinberg, S.M.; Grant, C.; Wright, G.; Varma, G.; et al. Dose-adjusted EPOCH-rituximab therapy in primary mediastinal B-cell lymphoma. N. Engl. J. Med. 2013, 368, 1408-1416. [CrossRef] [PubMed]

9. Melani, C.; Advani, R.; Roschewski, M.; Walters, K.M.; Chen, C.C.; Baratto, L.; Ahlman, M.A.; Miljkovic, M.D.; Steinberg, S.M.; Lam, J.; et al. End-of-treatment and serial PET imaging in primary mediastinal B-cell lymphoma following dose-adjusted EPOCH-R: A paradigm shift in clinical decision making. Haematologica 2018, 103, 1337-1344. [CrossRef] [PubMed]

10. Shah, N.N.; Szabo, A.; Huntington, S.F.; Epperla, N.; Reddy, N.; Ganguly, S.; Vose, J.; Obiozor, C.; Faruqi, F.; Kovach, A.E.; et al. $\mathrm{R}-\mathrm{CHOP}$ versus dose-adjusted R-EPOCH in frontline management of primary mediastinal B-cell lymphoma: A multi-centre analysis. Br. J. Haematol. 2018, 180, 534-544. [CrossRef] 
11. Chan, E.H.L.; Koh, L.P.; Lee, J.; De Mel, S.; Jeyasekharan, A.; Liu, X.; Tang, T.; Lim, S.T.; Tao, M.; Quek, R.; et al. Real world experience of R-CHOP with or without consolidative radiotherapy vs DA-EPOCH-R in the first-line treatment of primary mediastinal B-cell lymphoma. Cancer Med. 2019, 8, 4626-4632. [CrossRef]

12. Giulino-Roth, L.; O’Donohue, T.; Chen, Z.; Bartlett, N.L.; LaCasce, A.; Martin-Doyle, W.; Barth, M.J.; Davies, K.; Blum, K.A.; Christian, B.; et al. Outcomes of adults and children with primary mediastinal B-cell lymphoma treated with dose-adjusted EPOCH-R. Br. J. Haematol. 2017, 179, 739-747. [CrossRef]

13. Vassilakopoulos, T.P.; Mellios, Z.; Verigou, E.; Papageorgiou, S.; Chatzidimitriou, C.; Giatra, H.; Kalpadakis, C.; Gainaru, G.; Karakatsanis, S.; Xanthopoulos, V.; et al. Comparison of rituximab dose-adjusted EPOCH (R-DA-EPOCH) with rituximab-CHOP (R-CHOP) chemotherapy in primary mediastinal large B-cell lymphoma (PMLBCL). In Proceedings of the 24th European Hematology Association Congress, Amsterdam, The Netherlands, 13-16 June 2019; Volume 3, p. 100.

14. Engert, A.; Diehl, V.; Franklin, J.; Lohri, A.; Dorken, B.; Ludwig, W.D.; Koch, P.; Hanel, M.; Pfreundschuh, M.; Wilhelm, M.; et al. Escalated-dose BEACOPP in the treatment of patients with advanced-stage Hodgkin's lymphoma: 10 years of follow-up of the GHSG HD9 study. J. Clin. Oncol. Off. J. Am. Soc. Clin. Oncol. 2009, 27, 4548-4554. [CrossRef]

15. Engert, A.; Goergen, H.; Markova, J.; Pabst, T.; Meissner, J.; Zijlstra, J.M.; Kral, Z.; Eichenauer, D.A.; Soekler, M.; Greil, R.; et al. Reduced-Intensity Chemotherapy in Patients with Advanced-Stage Hodgkin Lymphoma: Updated Results of the Open-Label, International, Randomised Phase 3 HD15 Trial by the German Hodgkin Study Group. HemaSphere 2017, 1, e5. [CrossRef]

16. Bartlett, N.L.; Wilson, W.H.; Jung, S.H.; Hsi, E.D.; Maurer, M.J.; Pederson, L.D.; Polley, M.C.; Pitcher, B.N.; Cheson, B.D.; Kahl, B.S.; et al. Dose-Adjusted EPOCH-R Compared with R-CHOP as Frontline Therapy for Diffuse Large B-Cell Lymphoma: Clinical Outcomes of the Phase III Intergroup Trial Alliance/CALGB 50303. J. Clin. Oncol. Off. J. Am. Soc. Clin. Oncol. 2019, 37, 1790-1799. [CrossRef]

17. Cheson, B.D.; Fisher, R.I.; Barrington, S.F.; Cavalli, F.; Schwartz, L.H.; Zucca, E.; Lister, T.A. Recommendations for initial evaluation, staging, and response assessment of Hodgkin and non-Hodgkin lymphoma: The Lugano classification. J. Clin. Oncol. Off. J. Am. Soc. Clin. Oncol. 2014, 32, 3059-3068. [CrossRef] [PubMed]

18. Cheson, B.D.; Pfistner, B.; Juweid, M.E.; Gascoyne, R.D.; Specht, L.; Horning, S.J.; Coiffier, B.; Fisher, R.I.; Hagenbeek, A.; Zucca, E.; et al. Revised response criteria for malignant lymphoma. J. Clin. Oncol. Off. J. Am. Soc. Clin. Oncol. 2007, 25, 579-586. [CrossRef]

19. Vassilakopoulos, T.P.; Ferhanoglu, B.; Horowitz, N.; Mellios, Z.; Kaynar, L.; Zektser, M.; Symeonidis, A.; Piperidou, A.; Kalpadakis, C.; Akay, O.M.; et al. Rituximab-Dose-Adjusted Epoch (R-Da-EPOCH) in Primary Mediastinal Large B-Cell Lymphoma (PMLBCL): Real-Life Experience on 190 Patients from 3 Mediterranean Countries. Hematol. Oncol. 2021, 39, 234-235. [CrossRef]

20. Pinnix, C.C.; Ng, A.K.; Dabaja, B.S.; Milgrom, S.A.; Gunther, J.R.; Fuller, C.D.; Smith, G.L.; Abou Yehia, Z.; Qiao, W.; Wogan, C.F.; et al. Positron emission tomography-computed tomography predictors of progression after DA-R-EPOCH for PMBCL. Blood Adv. 2018, 2, 1334-1343. [CrossRef] [PubMed]

21. Wilson, W.H.; Grossbard, M.L.; Pittaluga, S.; Cole, D.; Pearson, D.; Drbohlav, N.; Steinberg, S.M.; Little, R.F.; Janik, J.; Gutierrez, M.; et al. Dose-adjusted EPOCH chemotherapy for untreated large B-cell lymphomas: A pharmacodynamic approach with high efficacy. Blood 2002, 99, 2685-2693. [CrossRef]

22. Dunleavy, K.; Fanale, M.A.; Abramson, J.S.; Noy, A.; Caimi, P.F.; Pittaluga, S.; Parekh, S.; Lacasce, A.; Hayslip, J.W.; Jagadeesh, D.; et al. Dose-adjusted EPOCH-R (etoposide, prednisone, vincristine, cyclophosphamide, doxorubicin, and rituximab) in untreated aggressive diffuse large B-cell lymphoma with MYC rearrangement: A prospective, multicentre, single-arm phase 2 study. Lancet. Haematol. 2018, 5, e609-e617. [CrossRef]

23. Menghrajani, K.; Zhang, Y.; Famulare, C.; Devlin, S.M.; Tallman, M.S. Acute myeloid leukemia with 11q23 rearrangements: A study of therapy-related disease and therapeutic outcomes. Leuk. Res. 2020, 98, 106453. [CrossRef]

24. Eichenauer, D.A.; Thielen, I.; Haverkamp, H.; Franklin, J.; Behringer, K.; Halbsguth, T.; Klimm, B.; Diehl, V.; Sasse, S.; Rothe, A.; et al. Therapy-related acute myeloid leukemia and myelodysplastic syndromes in patients with Hodgkin lymphoma: A report from the German Hodgkin Study Group. Blood 2014, 123, 1658-1664. [CrossRef]

25. Schoch, C.; Schnittger, S.; Klaus, M.; Kern, W.; Hiddemann, W.; Haferlach, T. AML with 11q23/MLL abnormalities as defined by the WHO classification: Incidence, partner chromosomes, FAB subtype, age distribution, and prognostic impact in an unselected series of 1897 cytogenetically analyzed AML cases. Blood 2003, 102, 2395-2402. [CrossRef]

26. Groschel, S.; Schlenk, R.F.; Engelmann, J.; Rockova, V.; Teleanu, V.; Kuhn, M.W.; Eiwen, K.; Erpelinck, C.; Havermans, M.; Lubbert, M.; et al. Deregulated expression of EVI1 defines a poor prognostic subset of MLL-rearranged acute myeloid leukemias: A study of the German-Austrian Acute Myeloid Leukemia Study Group and the Dutch-Belgian-Swiss HOVON/SAKK Cooperative Group. J. Clin. Oncol. Off. J. Am. Soc. Clin. Oncol. 2013, 31, 95-103. [CrossRef]

27. Aoki, T.; Izutsu, K.; Suzuki, R.; Nakaseko, C.; Arima, H.; Shimada, K.; Tomita, A.; Sasaki, M.; Takizawa, J.; Mitani, K.; et al. Prognostic significance of pleural or pericardial effusion and the implication of optimal treatment in primary mediastinal large B-cell lymphoma: A multicenter retrospective study in Japan. Haematologica 2014, 99, 1817-1825. [CrossRef] [PubMed]

28. Vassilakopoulos, T.P.; Michail, M.; Papageorgiou, S.; Kourti, G.; Angelopoulou, M.K.; Panitsas, F.; Sachanas, S.; Kalpadakis, C.; Katodritou, E.; Leonidopoulou, T.; et al. Identification of Very Low-Risk Subgroups of Patients with Primary Mediastinal Large B-Cell Lymphoma Treated with R-CHOP. Oncologist 2021, 26, 597-609. [CrossRef] [PubMed]

29. Hayden, A.R.; Tonseth, P.; Lee, D.G.; Villa, D.; Gerrie, A.S.; Scott, D.W.; Freeman, C.L.; Slack, G.W.; Farinha, P.; Skinnider, B.; et al. Outcome of primary mediastinal large B-cell lymphoma using R-CHOP: Impact of a PET-adapted approach. Blood 2020, 136, 2803-2811. [CrossRef] 
30. Armand, P.; Rodig, S.; Melnichenko, V.; Thieblemont, C.; Bouabdallah, K.; Tumyan, G.; Ozcan, M.; Portino, S.; Fogliatto, L.; Caballero, M.D.; et al. Pembrolizumab in Relapsed or Refractory Primary Mediastinal Large B-Cell Lymphoma. J. Clin. Oncol. Off. J. Am. Soc. Clin. Oncol. 2019, 37, 3291-3299. [CrossRef]

31. Zinzani, P.L.; Santoro, A.; Gritti, G.; Brice, P.; Barr, P.M.; Kuruvilla, J.; Cunningham, D.; Kline, J.; Johnson, N.A.; Mehta-Shah, N.; et al. Nivolumab Combined with Brentuximab Vedotin for Relapsed/Refractory Primary Mediastinal Large B-Cell Lymphoma: Efficacy and Safety from the Phase II CheckMate 436 Study. J. Clin. Oncol. Off. J. Am. Soc. Clin. Oncol. 2019, 37, $3081-3089$. [CrossRef] 